\title{
Mathematical Modelling of Impact of Education on Average Age at the First Marriage in Tanzania
}

\author{
Fatma S. Seif ${ }^{1, ~ *, ~ S a r a ~ A . ~ K h a m i s ~}{ }^{1}$, John K. Mduma ${ }^{2}$, Estomih S. Massawe ${ }^{3}$ \\ ${ }^{1}$ Department of Science, The State University of Zanzibar, Zanzibar, Tanzania \\ ${ }^{2}$ Department of Economics, University of Dar es Salaam, Dar es Salaam, Tanzania \\ ${ }^{3}$ Department of Mathematics, University of Dar es Salaam, Dar es Salaam, Tanzania
}

Email address:

fasasemo@hotmail.com (F. S. Seif), sakhamis3@gmail.com (S. A. Khamis)

${ }^{*}$ Corresponding author

\section{To cite this article:}

Fatma S. Seif, Sara A. Khamis, John K. Mduma, Estomih S. Massawe. Mathematical Modelling of Impact of Education on Average Age at the First Marriage in Tanzania. Pure and Applied Mathematics Journal. Vol. 6, No. 1, 2017, pp. 39-44. doi: 10.11648/j.pamj.20170601.15

Received: December 14, 2016; Accepted: January 6, 2017; Published: February 23, 2017

\begin{abstract}
This paper examines the impact of education on the average age at the first marriage to women in Tanzania. A mathematical model for the distribution of average age at the first marriage in Tanzania is established and the effect of education on the year at first marriage is estimated for the years 1999 and 2003/04. Both descriptive analysis and model estimate show that education level and education attainment have an impact on the average age at the first marriage. It is established that as one attains further studies, her age at first marriage is delayed. The model validation was presented graphically to illustrate the validity of the model where the proportion of ever married $p\left(a, x_{1}, x_{2}\right)$ fitted very closely to the empirical data.
\end{abstract}

Keywords: Impact of Education, Average Age, First Marriage

\section{Introduction}

Different interpretations exist on what marriage is. According to [1], marriage is defined as "the stage at which a man and a woman are socially or legally permitted to live together". According to [2], "Marriage is the only institution that allows two people to establish a very strong and enduring relationship that is fully backed by the law and society as a whole." According to these definitions a marriage cannot be accepted without being supported by law and society i.e. there are rules, norms and values which guide this institution. Marriage shall be entered into only with the free and full consent of the intending spouses, that is, a marriage can be established after the consent of the related couples only [3]. However in many cultures the consent of the couple only is not enough. The male parent of the bride must also give his consent.

Our societies have been characterized by low age at first marriage. According to [4], early marriage is the marriage of children and adolescent below the age of 18. The practice of early marriage is most common in Sub-Saharan Africa and
Southern Asia. A study conducted by [5] established that generally Tanzanian women enter the marriage institution at the very low age. The study emphasized that the minimum age is as low as six years.

Many studies have shown that low age at first marriage result into number of problems. "Early marriage contribute to series of negative consequences both for young girls and society in which they live." argues by [6]. Low ages at first marriage may also be associated with reduced education among girls, although it is difficult to ascertain the causality, this was narrated by [7]. A young bride may be less able to assert power and authority in her marriage especially given that women get married to men who are on average several years older.

Marriage without consent is widely thought to be major cause for most of the divorces, and many of early marriages are held without the consent of the girls, and this is the cause of instabilities of most marriages [4]. Instability is very common in early marriages, since the women enter the union by force and lack faithfulness and love to maintain the marriage so they run away back to their parents or to towns 
to search for a better living, getting employed as housemaids or becoming prostitutes.

[4] argued that due to physiological immaturity of sexual organs, some of the young married women faced health related problems like physical pain during intercourse, obstetric fistula due to early delivery, and other complications due to pregnancy. [4] also believes that due to age difference, early married women have and/or exercise lower sexual and reproductive rights than those who get married at appropriate ages and due to lack of education they have less ability to make decisions on matters related to reproductive health, such as the use of contraceptives and rights over sexuality. According to [8], early marriage certainly denies children of school age their right to the education they need for their personal development, preparation for adulthood, and effective contribution to the future wellbeing of their family and society.

There have been many contributions to reduce the problem of low age at first marriage such as education. Studies have indicated that as the level of education increases, the year at the first marriage is also affected. There is positive correlation between the number of years of education one gets and the average age at first marriage. According to [9], women with at least some secondary school education are less likely to get married at younger ages than women with less education. The study related to early marriage and female schooling attainment in Bangladesh was done by [10]. Their results indicate that each additional year that marriage is delayed is associated with 0.22 additional year of schooling and 5.6 percent of higher literacy. It is found by [1] that, as educational levels increase, ages at marriage also increases. In this paper it is intended to develop and analyze a model on the impact of education on the average age at the first marriage in Tanzania. A model for fitting the age pattern of first marriage called PICRATE model is developed by [11]. PICRATE meaning "Phased-In-Constant Rate". In this paper, it is intended to modify the work by [11] by incorporating the impact of education at first marriage for women.

\section{Model Formulation}

A model for the impact of education on average age at the first marriage for women is formulated and analyzed. According to [11], the PICRATE model is given by the formula:

$$
p(a)=p_{\max }\left\{1-\exp \left[-r_{\max }\left(a-a_{0}\right)+I\left(r_{\max }\left(a-a_{0}\right)\right)\right]\right\}
$$

where

$a$ is age (continuous, measured in years),

$a_{0}$ is the age at which marriage begin,

$p(a)$ is the proportion of ever married at age $a$,

$p_{\max }$ is the proportion that will eventually marry (maximum value of $p$ ),

$r_{\max }$ is the maximum age specific first marriage recruitment rate.

$$
I(x)=\int_{0}^{x} \exp \left(-\frac{1}{2} u^{2}\right) d u=\sqrt{2 \pi}\left[N_{C}(x)-\frac{1}{2}\right]
$$

and $N_{c}(x)$ is the cumulative normal distribution function with mean 0 and standard deviation 1 .

The curve for $p(a)$ describes the history of first marriages in the cohort, but for a stable population it also describes the age-specific ever-married proportion for a population. Note that the curve is determined by the three parameters $a_{0}, r_{\max }$, and $p_{\max }$ [11].

In developing the model of the impact of education on average age at the first marriage, all parameters in PICRATE model are retained except $a_{0}$ which is treated as a function of social economic variable (linear function of education).

In formulating the model, the following assumptions are taken into consideration:

- The model is correct. Nonlinear regression adjusts the variables in the equation model chosen to minimize the sum-of-squares. It does not attempt to find a better equation.

- The variability of values around the curve follows approximately a Gaussian distribution.

- The Standard Deviation of the variability is the same everywhere, regardless of the value of independent variables. If the Standard Deviation is not constant but rather is proportional to the value of dependent variable, the data are weighed to minimize the sum-of-squares of the relative distances.

- The model assumes that independent variables are known exactly. This is rare but it is sufficient to assume that any imprecision in measuring the independent variable is very small compared to the variability in dependent variable.

- Lastly, the errors are independent. The deviation of each value from the curve should be random, and should not be correlated with the deviation of the previous or next value. The assumption is violated if there is any carryover from one sample to the next [12].

The results of nonlinear regression are meaningful only if these assumptions are true (or nearly true).

Assuming that the social-economic factors affect the age at the first marriage linearly, then $a_{0}$, the age at which marriage begin is assumed for simplicity to be a linear function of education which can be expressed as:

$$
a_{0}=b_{0}+b_{1} x_{1}+b_{2} x_{2}
$$

where,

$a_{0}$ as defined earlier, is the age at which marriage begin,

$b_{0}, b_{1}$ and $b_{2}$ are parameters to be estimated,

$x_{1}$ and $x_{2}$ are dummy variables, where $x_{1}$ represents education at primary level, while $x_{2}$ represents education at secondary level. The non education groups form the reference group. 
Then the modified model will be:

$$
p\left(a, x_{1}, x_{2}\right)=p_{\max }\left\{1-\exp \left[\begin{array}{l}
-r_{\text {max }}\left(a-\left(b_{0}+b_{1} x_{1}+b_{2} x_{2}\right)\right) \\
+I\left(r_{\text {max }}\left(a-\left(b_{0}+b_{1} x_{1}+b_{2} x_{2}\right)\right)\right)
\end{array}\right]\right\}
$$

\section{Estimation of the Model Parameters}

We consider the nonlinear equation

$$
Y=f\left(X_{1}, X_{2}, \ldots, X_{k}, \beta_{1}, \beta_{2}, \ldots, \beta_{p}\right)+\varepsilon
$$

Any nonlinear function can be expressed as a Taylor series expansion. The Taylor series expansion to a set of initial values $\beta_{1.0}, \ldots, \beta_{p . .0}\left(p_{\max }, r_{\max }, a_{0}\right)$ for the coefficients $\beta_{i}, \ldots, \beta_{p}\left(p_{0}, r_{0}, a_{0}\right)$ is given by

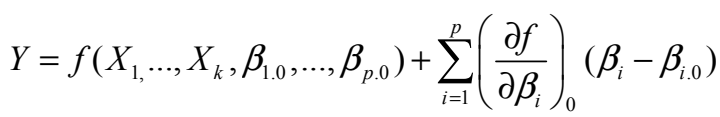

$$
\begin{aligned}
& +\frac{1}{2} \sum_{i=1}^{p} \sum_{j=1}^{p}\left(\frac{\partial^{2} f}{\partial \beta_{i} \beta_{j}}\right)_{0}\left(\beta_{i}-\beta_{i .0}\right)\left(\beta_{j-} \beta_{j .0}\right)+\ldots .+\varepsilon
\end{aligned}
$$

The subscript 0 on the partial derivatives denotes that these derivatives are evaluated at $\beta_{1}=\beta_{1.0}, \ldots, \beta_{p}=\beta_{p .0}$. A linear approximation to the nonlinear function (5) is given by the first two terms in the Taylor series expansion (6) i.e.

$$
\begin{aligned}
& Y-f\left(X_{1}, \ldots, X_{k}, \beta_{1.0}, \ldots, \beta_{p .0}\right) \\
& +\sum_{i=1}^{p} \beta_{i .0}\left(\frac{\partial f}{\partial \beta_{i}}\right)_{0}=\sum_{i=1}^{p} \beta_{i}\left(\frac{\partial f}{\partial \beta_{i}}\right)_{0}+\varepsilon
\end{aligned}
$$

From the basic model (1), we have

$$
\begin{aligned}
& p(a)-p_{0}\left\{1-\exp \left[-r_{o}\left(a-a_{0}^{\prime}\right)+I\left(r_{0}\left(a-a_{0}^{\prime}\right)\right)\right]\right\} \\
& +p_{0}\left(\frac{\partial p(a)}{\partial p_{\max }}\right)_{0}+r_{0}\left(\frac{\partial p(a)}{\partial r_{\max }}\right)_{0}+ \\
& a_{0}^{\prime}\left(\frac{\partial p(a)}{\partial a_{0}}\right)_{a_{0}^{\prime}}=p_{\max }\left(\frac{\partial p(a)}{\partial p_{\max }}\right)_{p_{0}} \\
& +r_{\max }\left(\frac{\partial p(a)}{\partial r_{\max }}\right)_{r_{0}}+a_{0}\left(\frac{\partial p(a)}{\partial a_{0}}\right)_{a_{0}^{\prime}}+\varepsilon
\end{aligned}
$$

where

$p_{0}$ is the initial guess value of $p_{\max }$,

$r_{0}$ is the initial guess value of $r_{\max }$,

$a_{0}$ as defined earlier, is the age at which marriage begin.

The partial derivatives in (8) are given by $\frac{\partial p(a)}{\partial p_{\max }}=1-\exp \left[-r_{\max }\left(a-a_{0}\right)+I\left(r_{\max }\left(a-a_{0}\right)\right)\right]$

$$
\begin{aligned}
& \frac{\partial p(a)}{\partial r_{\text {max }}}=-p_{\max }\left[\left(-a+a_{0}\right)+\left(a-a_{0}\right) e^{-\frac{1}{2} r_{\max }^{2}\left(a-a_{0}\right)^{2}}\right] \\
& \times \exp \left[-r_{\text {max }}\left(a-a_{0}\right)+I\left(r_{\text {max }}\left(a-a_{0}\right)\right)\right] \\
& \frac{\partial p(a)}{\partial a_{0}}=p_{\text {max }}\left[r_{\text {max }}-2 r_{\text {max }} e^{-\frac{1}{2} r_{\text {max }}^{2}\left(a-a_{0}\right)^{2}}\right] \\
& \times \exp \left[-r_{\text {max }}\left(a-a_{0}\right)+I\left(r_{\text {max }}\left(a-a_{0}\right)\right)\right]
\end{aligned}
$$

We substitute the expressions for, $\frac{\partial p(a)}{\partial p_{\max }}, \frac{\partial p(a)}{\partial r_{\max }}$ and $\frac{\partial p(a)}{\partial a_{0}}$ in equation (8), to get parameter estimates for, $p_{\max }$, $r_{\max }$ and $a_{0}$. The estimated coefficients values for, $p_{\max }$, $r_{\max }$ and $a_{0}$ which are denoted by $p_{0}, r_{0}$, and $a_{0}$ are used as a new set of initial estimates, and the nonlinear equation is linearized around these values. The result is a new linear regression equation. From equation (8) we then have

$$
\begin{gathered}
p(a)-p_{0}\left(1-\exp \left[-r_{0}\left(a-a_{0}^{\prime}\right)+\sqrt{2 \pi}\left(N_{c}(x)-\frac{1}{2}\right)\right]\right) \\
+p_{0}\left(1-\exp \left[-r_{0}\left(a-a_{0}^{\prime}\right)+\sqrt{2 \pi}\left(N_{c}(x)-\frac{1}{2}\right)\right]\right) \\
-r_{0} p_{0}\left[\left(-a+a_{0}^{\prime}\right)+\left(a-a_{0}^{\prime}\right) \exp \left(-\frac{1}{2} r_{0}^{2}\left(a-a_{0}\right)^{2}\right)\right] \\
\times \exp \left[-r_{0}\left(a-a_{0}^{\prime}\right)+\sqrt{2 \pi}\left(N_{c}(x)-\frac{1}{2}\right)\right]+ \\
\quad a_{0}^{\prime} p_{0} r_{0}\left[1-2 \exp \left(-\frac{1}{2} r_{0}^{2}\left(a-a_{0}\right)^{2}\right)\right] \times \\
\quad \exp \left[-r_{0}\left(a-a_{0}^{\prime}\right)+\sqrt{2 \pi}\left(N_{c}(x)-\frac{1}{2}\right)\right]= \\
P_{\max }\left[1-\exp \left(-r_{o}\left(a-a_{0}\right)+\left(\sqrt{2 \pi}\left(N_{C}(x)-\frac{1}{2}\right)\right)\right]\right. \\
+a_{0} p_{0} r_{0}\left[1-2 \exp \left(-\frac{1}{2} r_{0}^{2}\left(a-a_{0}\right)^{2}\right) \times\right. \\
\quad r_{\max } P_{o}\left(a-a_{0}\right)+\left(a-a_{o}\right) \exp \left(-\frac{1}{2} r_{0}^{2}\left(a-a_{0}\right)^{2}\right) \\
\times \exp \left[-r_{o}\left(a-a_{0}\right)\right]+\sqrt{2 \pi}\left(N_{c}(x)-\frac{1}{2}\right)
\end{gathered}
$$

After simplifying this equation, we let $p_{0}=1, r_{0}=0.88$ and $a_{0_{0}}=15$ be a set of initial estimates. Substitute these values in equation (9), and then apply ordinary least square to this equation to get a new set of coefficient estimates 
$p_{1}, r_{1}$ and $a_{0_{1}}$. The process of relinearization is repeated until convergences is attained and at this stage the values of parameters $p_{\max }, \quad r_{\max }$ and $a_{0}$ will be attained. SPSS Software is used to estimate these parameters.

At the second stage we use the modified model to estimate parameters which include parameters of the function of education, that is, we estimate parameters $p_{\max }, r_{\max }, b_{0}, b_{1}$ and $b_{2}$ by using the same procedure of least square method as it was used to estimate parameters of PICRATE model. On estimating the modified model parameters, STATA Software is used.

Two datasets of the Tanzania Demographic and Health surveys of 1999 and 2003-04 are used.

\section{Analysis of the Model}

To assess the effect of education on the age at the first marriage, a series of variables (dummy or indicators) for the level of education completed by respondents was created. The variables were created according to the following categories of education levels: no education, some or completed primary education, some or completed secondary education, higher education. For the purpose of the statistical analysis the no education category was set as a reference category.

Estimation of the parameters for the modified PICRATE model was done by using the STATA computer package for the data of the years 1999 and 2003/04 provided by the Demographic and Health Surveys (DHS). The estimation yielded the results which are the same for the two years. The optimal results were obtained after 12 iterations for the data of the year 1999 and 10 iterations for the data of the year $2003 / 04$. This was due to the nature of non linearity of the function that was estimated.

\subsection{Descriptive Analysis of Education Level and Age at First Marriage}

The results for the education covariates are shown below.

Table 1. Distribution of age at the first marriage by education level.

\begin{tabular}{lllll}
\hline YEAR & Education level & Mean & Median & Mode \\
\hline 1999 & No education & 16 & 16 & 15 \\
& Primary & 18 & 17 & 17 \\
& Secondary & 19 & 19 & 18 \\
& Higher Education & 25 & 25 & 22 \\
\multirow{2}{*}{$003 / 04$} & No education & 17 & 17 & 15 \\
& Primary & 18 & 18 & 17 \\
& Secondary & 22 & 21 & 21 \\
& Higher Education & 24 & 23 & 23 \\
\hline
\end{tabular}

Table 1 summarizes the findings from the descriptive analysis of the data. For both survey years, the age at the first marriage was lower for respondents with no education compared to those with education. In both years, the mean age at first marriage increases gradually as the level of education increases as seen in Figure 1 and Figure 2 below.

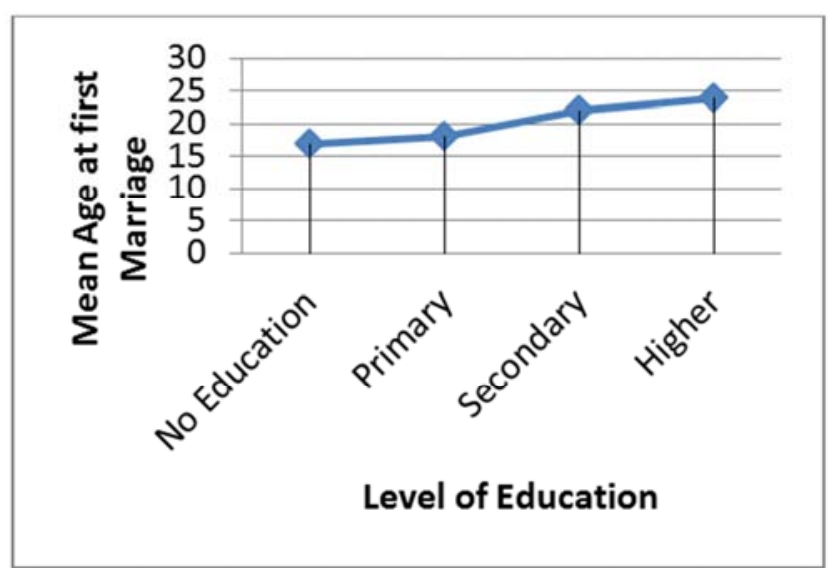

Figure 1. Variation in the mean age at the first marriage by Levels of education in Tanzania for the data of 1999.

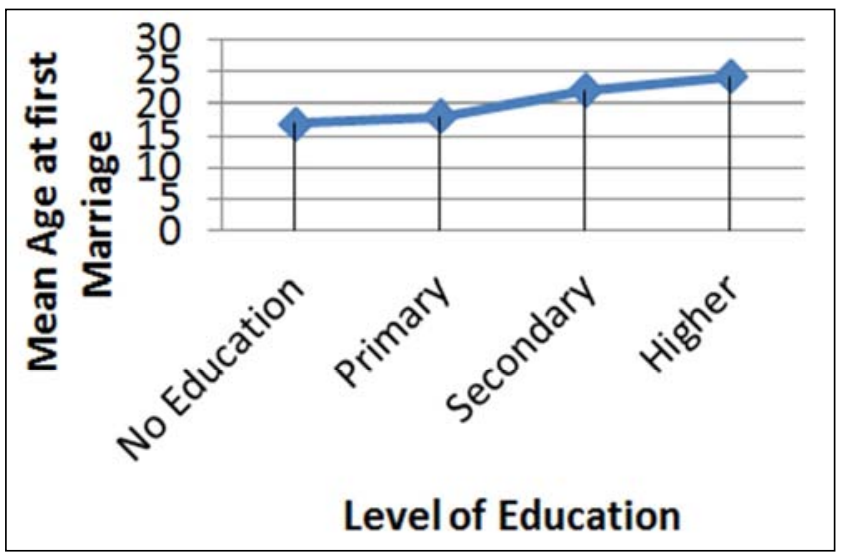

Figure 2. Variation in the Mean Age at First Marriage by Levels of Education in Tanzania for the data of 2003/04.

Table 2. Inter-Year Comparison of Mean Age at First Marriage.

\begin{tabular}{lll}
\hline & $\mathbf{1 9 9 9}$ & $\mathbf{2 0 0 3 / 0 4}$ \\
\hline No education & 16 & 17 \\
Primary & 18 & 18 \\
Secondary & 19 & 22 \\
Higher & 25 & 24 \\
\hline
\end{tabular}

Table 3. Distribution of age at first marriage by education attainment.

\begin{tabular}{llllll}
\hline Year & $\begin{array}{l}\text { Educational } \\
\text { attainment }\end{array}$ & Mean & Median & Mode & Std Dev \\
\hline 1999 & No education & 16 & 16 & 15 & 4 \\
& Incomplete primary & 17 & 17 & 15 & 3 \\
& Complete primary & 18 & 18 & 17 & 3 \\
& Incomplete secondary & 19 & 19 & 18 & 4 \\
& Complete secondary & 23 & 23 & 22 & 2 \\
& Higher & 25 & 25 & 22 & 4 \\
& No education & 17 & 17 & 15 & 4 \\
& Incomplete primary & 17 & 17 & 17 & 3 \\
& Complete primary & 19 & 18 & 17 & 3 \\
& Incomplete secondary & 21 & 20 & 18 & 4 \\
& Complete secondary & 24 & 24 & 24 & 4 \\
& Higher & 24 & 23 & 23 & 3 \\
\hline
\end{tabular}


From these observations, age at first marriage can be regarded as increasing function of education level or education attainment.

\subsection{Results of Estimating Parameters}

This section presents results of the empirical models of age at first marriage. The model is a modified PICRATE to the case of Tanzania. Fitting the model was done by non linear least square technique using the STATA Software.

Table 4 and table 5 below show results of modified PICRATE model in Tanzania from TDHS data in 1999. Displayed in the table are model summary and parameter estimates (coefficients) with their significance/ $p$-values.

Table 4. Model Summary (1999).

\begin{tabular}{ll}
\hline Number of observations & $\mathbf{4 0 2 9}$ \\
\hline $\mathrm{F}(5,4024)$ & 885384.75 \\
Prob $>$ F & 0.0000 \\
R-squared & 0.9991 \\
Adj R-squared & 0.9991 \\
Root MSE & 0.0246 \\
Res. dev. & -18431.83 \\
\hline
\end{tabular}

Table 5. Parameter Estimates (1999).

\begin{tabular}{llll}
\hline Parameter & Coef. & Std. Err & $\mathbf{P}>|\mathbf{t}|$ \\
\hline$p$ & 1.0043 & 0.0007 & 0.000 \\
$r$ & 0.2050 & 0.0006 & 0.000 \\
$b_{\mathrm{n}}$ & 3.0980 & 0.0439 & 0.000 \\
$\mathrm{~b}_{1}$ & 0.0182 & 0.0147 & 0.215 \\
$\mathrm{~b}_{2}$ & 0.0896 & 0.0217 & 0.000 \\
\hline
\end{tabular}

The F-value is 885384.75 and its probability (p-value) is 0.000 implying that the model is significant at $1 \%$ level since p-value $<0.05$. The coefficient of determination, R-squared, is 0.9991 implying that the variation $(99.91 \%)$ in the ever married proportion model is explained by the covariates, namely education levels, in the form of a prescribed model (PICRATE model). This linear function of education is represented by three parameters which are $b_{0}, b_{1}$ and $b_{2}$.

Out of the five parameters estimated in the model, four of them are statistically significant. These are

$p_{\max }(p$-value $=0.000<0.05), r_{\max }(p$-value $=0.000<0.05)$, $b_{0}(p$-value $=0.000<0.05)$ and $b_{2}(p$-value $=0.000<0.05)$. $b_{1}$ is to be statistically insignificant ( $p$-value $=0.215>0.05$ ). The values of the significant parameter estimates for the 1999 data are therefore

$$
p_{\max }=1.0043, r_{\max }=0.2050, b_{0}=3.098, b_{2}=0.8955 \text {. }
$$

Table 6 and Table 7 below show the results of the modified PICRATE model in the year 2003/04.

Table 6. Model Summary (2003/04).

\begin{tabular}{ll}
\hline Number of observations & $\mathbf{6 8 6 3}$ \\
\hline $\mathrm{F}(5,6858)$ & 850853.05 \\
Prob $>$ F & 0.0000 \\
R-squared & 0.9984 \\
\hline
\end{tabular}

\begin{tabular}{ll}
\hline Number of observations & $\mathbf{6 8 6 3}$ \\
\hline Adj R-squared & 0.9984 \\
Root MSE & 0.0326 \\
Res. dev. & -27507.55 \\
\hline
\end{tabular}

Table 7. Parameter Estimates (2003/04).

\begin{tabular}{llll}
\hline Parameter & Coef. & Std. Err & $\mathbf{P}>|\mathbf{t}|$ \\
\hline$p$ & .9987 & .0007 & 0.000 \\
$r$ & .2017 & .0006 & 0.000 \\
$b_{\mathrm{n}}$ & 3.0482 & .0457 & 0.000 \\
$\mathrm{~b}_{1}$ & -.0477 & .0152 & 0.002 \\
$\mathrm{~b}_{2}$ & .0779 & .0221 & 0.000 \\
\hline
\end{tabular}

The F-value is 850853.05 and its probability (p-value) is 0.000 implying that the model is significant at 5\% level since p-value $<0.05$. The coefficient of determination, R-squared, is 0.9984 implying that the variation $(99.8 \%)$ in the ever married proportion model is explained by the by covariates, namely education levels, in the form of a prescribed model (PICRATE model). Again this linear function of education is represented by three parameters which are $b_{0}, b_{1}$ and $b_{2}$.

All five parameters in the model are statistically significant with $p<0.05$ for each. The values of these parameter estimates for 2003/04 data are

$$
\begin{gathered}
p_{\max }=0.9987(p-\text { value }=0.000<0.05) \\
r_{\max }=0.2017(p-\text { value }=0.000<0.05) \\
b_{0}=3.0482(p-\text { value }=0.000<0.05) \\
b_{1}=-0.0477(p-\text { value }=0.002<0.05) \text { and } \\
b_{2}=0.7790(p-\text { value }=0.000<0.05) .
\end{gathered}
$$

\section{Empirical Validation of the Modified Picrate Model}

Figure 3 and Figure 4 show the comparisons of the empirical data with the data computed by the modified PICRATE model for the years 1999 and 2003/04 respectively.

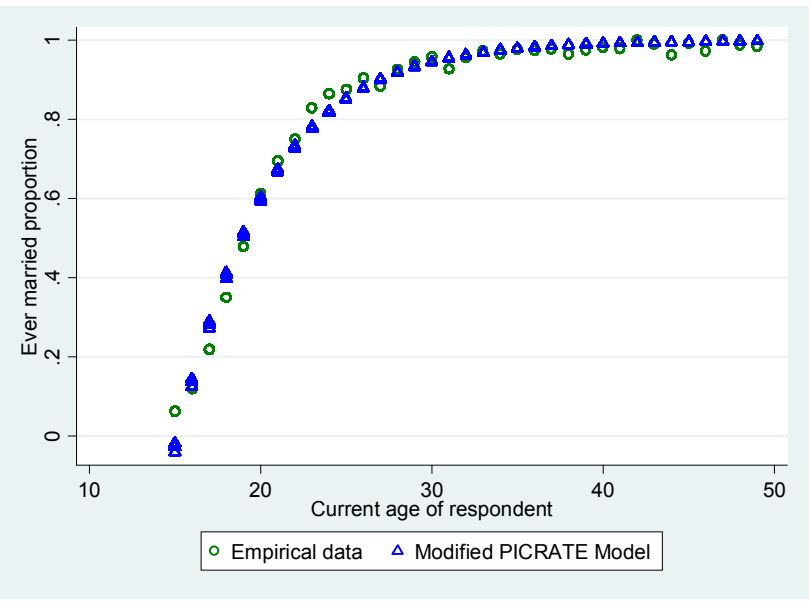

Figure 3. Fitting empirical data with modified PICRATE model (1999). 


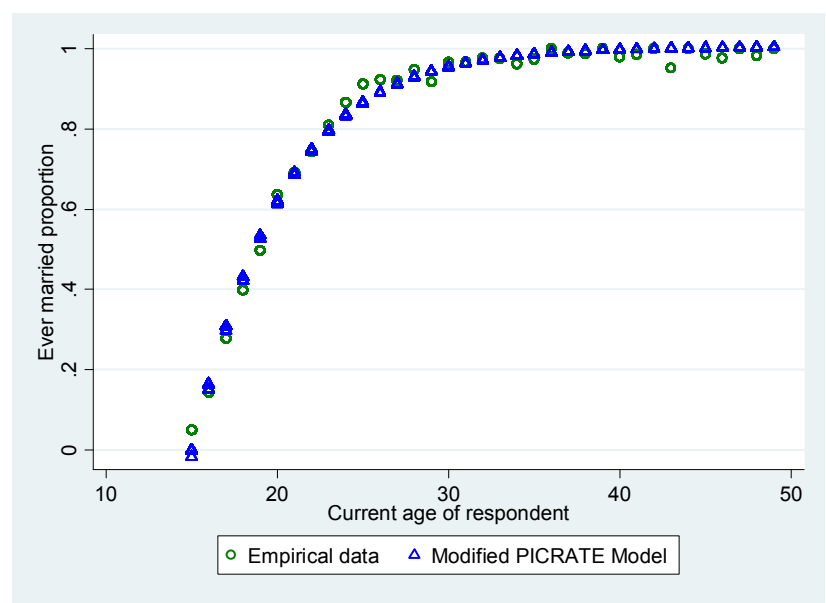

Figure 4. Fitting empirical data with modified PICTRATE Model $(2003 / 04)]$.

From the Figure 3 and Figure 4, the modified PICRATE model agrees very closely to the empirical data. These results show that education level and education attainment has an impact on the average age at the first marriage in Tanzania. Also these findings do not imply on the quality of education in Tanzania, they show that as girls attains further studies, her age at first marriage is delayed. Delayed marriages may have result in reduction in fertility rate and contribute in the reduction in population growth rate.

\section{Conclusions}

In this paper, a model of the impact of education on the average age at the first marriage was developed and analyzed. At the first stage PICRATE function $\hat{p}(x)$ (cumulative probability distribution function) and $f(x)$ (probability distribution function) were considered. As an extension of the standard PICRATE model, it was assumed that the social economic variable (education) affect the age at the first marriage linearly. Consequently, the age at which marriage begin in the PICRATE model was assumed for simplicity to be a linear function of education. By doing that we obtained a modified PICRATE model.

The parameters of modified PICRATE model were then estimated by STATA Software. Optimal solution was obtained after 12 iterations for the data of 1999 and after 7 iterations for the data of 2003/04. In both cases almost all estimated parameters were found to be statistically significant except $b_{1}$ which is one of the parameter of linear function of education which estimates the effect of primary education on the mean of the first year of marriage. This parameter was found to be significant in 2003/04 and insignificant in 1999 based on the reported $p$-values and selected level of significance.

Generally, descriptive analysis of education level / educational attainment and age at first marriage shows that education level and educational attainment have significant impact on the average age at the first marriage. As one gets further education, her age at the first marriage is delayed significantly.
It is seen that high education level has a very high impact on the delay of early marriage. It is appropriate for the government to formulate policies which will encourage girls to get further studies. This will protect them from early marriages. The education policy needs to be reviewed. For example the level of minimum education should be increased from standard seven to form four. This will increase the number of years in which the girls are in school and hence delay early marriages.

\section{References}

[1] Akter S, Rahman MM (2009), Direct and Indirect Effects of Socioeconomic Factors on Age at First Marriage in Slum Areas in Chinese, Journal of Population, Resources and Enviromental Bangladesh, University of Rajshahi, Vol 7, No. 3 (p. 79-82).

[2] Walsh J (2008) Importance of Marriage, Retrieved on 27/9/2010 from

http://www.iguides.org/articles/articles/832/1/Importance-ofMarriage-to-Society/Page1.html.

[3] Universal Declaration of Human Rights (1948) United Nation (UN), Retrieved on 25/10/2010 from

Article16No.2http://www.jus.uio.no/lm/un.universal.declarati on.of.human.rights.1948/portrait.a4.pdf.

[4] Pathfinder International (2006) Report on causes and consequences of early marriage in Amhara region, Retrieved on 1/10/2010from http://www.pathfind.org/site/DocServer, Ethiopia.

[5] Ngalinda, I (1998) Age at First Birth, Fertility, and Contraception in Tanzania, Unplished PHD thesis, Berlin.

[6] Bayisenge, J (2010) Early Marriage as a Barrier to Girl's Education, Retrieved on 1/10/2010

fromwww.ifuw.org/fuwa/docs/Early-marriage2.pdf.

[7] Beegle K, Krutikova S (2008) Adult mortality and Children's transition into marriage in Demographic Research, Journal of Peer -Reviewed Research and Commentary in the Population Science, Max Planck Institute for Demographic Research Konrad-Zuse Str. 1, D-18057 Rostock, Germany,Vol19, Art 42, pp1551-1574.

[8] UNICEF (2001) The State of the World's Children.

[9] Singh S, Samara R (1996) Early Marriage Among Women in Developing Countries, Journal of International Family Planning Perspectives, Guttmacher Institute, New York, Vol 22, No. 4 pp148-157 \& 175 .

[10] Erica F, Attila A (2008)Early Marriage, Age of Menarche, and Female School Attainment in Bangladesh, Journal of Political Economy, The University of Chicago, Vol 116, No. 5, pp. 881930.

[11] Matthew AP, Leclerc PM, Garenne ML (2009) The Picrate Model For Fitting The Age Pattern Of First Marriage, Journal of Math. Sci. hum / Mathematics and Social Sciences (47e année, $n^{\circ} 186,2009$ (2), p. 17-28).

[12] Motlusky H (1995) The Graph Pad Guide to Nonlinear Regression, Retrieved on 20/3/2011 from http://www.graphpad.com/www/nonling3.htm. 